Cuadernos de Lingüística Hispánica N. ${ }^{\circ} 22$

ISSN 0121-053X

Julio-Diciembre 2013; pp. 13-26

\title{
Estudio de la focalización prosódica en el habla de Maracay*
}

\author{
DAMELYS CAROLINA DELGADO YUSTE* \\ damelysdelgado05@hotmail.com \\ YURBITAY DEL VALLE INCIARTE ASUAJE ${ }^{* * *}$ \\ yurbitay.inciarte21@gmail.com
}

Recepción: 14 de abril de 2013

Aprobación: 27 de junio de 2013

* Artículo de investigación científica.

** Maestranda en Linguística, UPEL - Maracay; Licenciada en Lengua y Literatura; profesora en la Universidad Pedagógica Experimental Libertador, Instituto Pedagógico Rural "El Mácaro" sede: Turmero - Edo., Aragua, Venezuela; investigadora en temas de Fonética y Fonología, Análisis del discurso y tipología textual, Semántica y Pragmática.

***: Maestranda en Linguística, UPEL- Maracay; Licenciada en Lengua y Literatura; profesora en la Universidad Pedagógica Experimental Libertador, Instituto Pedagógico Rural "El Mácaro", sede: Turmero- Edo, Aragua, Venezuela; investigadora en temas de Fonética y Fonología, Análisis del discurso y tipología textual, Semántica y Pragmática. 


\title{
Resumen
}

Esta investigación comprende un estudio de la entonación, centrado específicamente en analizar los acentos tonales de la focalización en los enunciados del Corpus Sociolinguístico de la Ciudad de Maracay, Venezuela. La muestra está conformada por 162 enunciados, se identificaron 135 con información nueva y 27 con información dada. Se han procesado los enunciados con información nueva, es decir, un $83.3 \%$ de la muestra oral total y en ellos se presentaron tres tipos de acentos tonales: $\mathrm{H}^{*}, \mathrm{~L}+\mathrm{H}^{*}$ y H+L* $\mathrm{L}^{*}$. El tono predominante fue el acento $\mathrm{H}^{*}$ en 133 enunciados. En función de estos resultados se infiere que el acento monotonal alto $\left(\mathrm{H}^{*}\right)$ es un marcador del foco en la información nueva, y pragmáticamente esto significa que para el hablante, la mayor relevancia informativa se encuentra en aquello introducido por primera vez en el acto locutivo.

Palabras clave: entonación, focos, habla espontánea.

\section{Study of prosodic focalization in the speech of Maracay}

\begin{abstract}
This research article is a study on intonation, concentrating on the analysis of tonal accents in the focalization of statements from the sociolinguistic corpus of the city of Maracay. The sample includes 162 statements, 135 containing new information and 27 containing existing information. Currently, the former have been processed, which represent $83.3 \%$ of the total sample. In this percentage, three types of tonal accents were identified: $\mathrm{H}^{*}, \mathrm{~L}+\mathrm{H}^{*}$ and $\mathrm{H}+\mathrm{L}^{*}$. $\mathrm{H}^{*}$ was the predominant accent; present in 133 statements. Based on those results shows that high mono-tonal accent $\left(\mathrm{H}^{*}\right)$ is a marker of focus in new information. Pragmatically, this means that, for the speaker, the most relevant information is found in what is introduced in the locutionary act for the first time.
\end{abstract}

Key words: Intonation, focus, spontaneous speech. 


\section{Étude la focalisation prosodique dans la parole à Maracay}

\section{Résumé}

Cette recherche comprend une étude de l'intonation, centrée de manière spécifique, sur l'analyse de l'accent tonal de la focalisation dans les énoncés du Corpus Sociolinguistique de la ville de Maracay (s.d.). L'échantillon est composé par 162 énoncés, dont 135 ayant une information nouvelle et 27 ayant une information donnée. Actuellement on a traité les énoncés ayant une information nouvelle, c'est-à-dire, $83.3 \%$ de l'échantillon oral total et on y a détecté trois types d'accents tonals: $\mathrm{H}^{*}, \mathrm{~L}+\mathrm{H}^{*}$ y H$+\mathrm{L}^{*}$. L'accent $\mathrm{H}^{*}$ a été le ton prédominant en 133 énoncés. En fonction de ce ci, on infère que l'accent mono tonal haut $\left(\mathrm{H}^{*}\right)$ es une marque du focus dans l'information nouvelle et au niveau pragmatique, cela veut dire que pour celui qui parle, la relevance informative la plus importante se trouve dans ce qui est introduit pour la première fois dans l'acte locutoire.

Mots Clés: intonation, focus, parole spontanée.

\section{Estudo da focalização prosódica na fala de Maracay}

\section{Resumo}

A pesquisa desenvolve um estudo da entonação centralizada nas analises dos acentos tonais na focalização dos enunciados do Corpus Sociolinguístico da Cidade de Maracay (sf). As amostras foram obtidas de 162 enunciados, identificaram-se 135 com novas informações e 27 com informações antecipadas. Na atualidade processaram-se os enunciados com informação nova, quer dizer, $83,3 \%$ da totalidade das amostras orais tendo como resultados três tipos de acentos tonais: $\mathrm{H}^{*}, \mathrm{~L}+\mathrm{H}^{*}$ e $\mathrm{H}+\mathrm{L}^{*} .0$ tono predominante foi o acento $\mathrm{H}^{*}$ em 133 enunciados. Em função dos resultados se infere que 0 acento monotonal alto $\left(\mathrm{H}^{*}\right)$ é um marcador do foco na informação nova e pragmaticamente poder-se-ia dizer que para o falante, a maior relevância informativa se encontra naquilo introduzido pela primeira vez no ato de dicção.

Palabras Chave: Entonação, focos, fala, espontânea. 


\section{Introducción}

Las investigaciones sobre los elementos prosódicos en el habla oral han sido de gran importancia tanto en España como en países hispanoamericanos. En dichos estudios se ha analizado el comportamiento de las prominencias tonales tanto en frases predeterminadas como en el discurso espontáneo, también se ha enfocado en el análisis entonativo de dialectos desde la perspectiva comparativa y el estudio de casos particulares en variedades lingüísticas de Hispanoamérica. Esta investigación se centra en el análisis de los acentos tonales de la focalización prosódica en los enunciados del Corpus Sociolingüístico de Maracay (CSMC). Su propósito es identificar y describir la altura tonal o picos de los enunciados en el CSMC, para luego explicar la función pragmática de los patrones tonales de los focos.

\section{Prosodia y sus elementos}

Existe una diversidad de términos asociados a la definición de la prosodia, y en la actualidad la conceptualización de esta subyace en el conocimiento profundo de la identidad melódica de las lenguas y los dialectos, es decir, en el procesamiento complejo de elementos que van más allá de combinaciones morfosintácticas. Para Mora y Asuaje (2009):

La prosodia es la disciplina que se encarga de describir melódica y rítmicamente los sonidos del habla: esa especie de 'acento' que nos permite identificar a nuestro interlocutor, si es hombre o mujer, la clase social a la cual pertenece, si está triste 0 , incluso, si es extranjero. La acentuación, el ritmo y la entonación son las cualidades sonoras responsables de esa 'música' que escuchamos cuando alguien nos habla. (p. 18).

De esta manera, se explica que la prosodia es una entidad propia de la práctica comunicativa, la cual engloba tres condiciones precisas para producir efectos en los interlocutores según sea la emisión melódica proyectada en los sonidos producidos. Por ello, se evidencia claramente que esta maneja un enlace coherente e intencional de los elementos linguísticos, los cuales le permiten así marcar otros extralingüísticos. La prosodia va a estar, a su vez, integrada por diversos parámetros como lo son el acento, la entonación y el ritmo. 
La prosodia como se ha explicado, está conformada por tres elementos que a su vez forman sus unidades de estudio. Estos elementos «[... ] lejos de constituir un adorno, son precisamente los que organizan el hilo de sonidos que percibimos y tienen a su cargo una parte importante de la información textual [...]» (Álvarez, 2008, p. 86). Es decir, el carácter suprasegmental viene determinado por su función expresiva con sentido significativo y comunicativo.

Así, los rasgos extralingüísticos de la prosodia se determinan a través de tres elementos suprasegmentales que son descritos a continuación:

\subsection{El acento}

Es un elemento condicionado por la función suprasegmental, que en términos de Quilis (1981) es definido como:

Un rasgo prosódico que permite poner de relieve una unidad lingüística superior al fonema [sílaba, morfema...] [...] para diferenciarlas de otras unidades lingüísticas del mismo nivel. Por lo tanto, el acento se manifiesta como un contraste entre unidades acentuadas y unidades inacentuadas (p. 310).

Mora y Asuaje (2009) clasifican los acentos de la lengua española, en tres: léxico 0 de palabra con función distintiva en significación según la posición del acento; de grupo 0 nuclear, aquel que posee características acústicas marcadas, las cuales permiten distinguir zonas dialectales. Y, por último, el enfático o de insistencia, originado por fines pragmáticos, que permite cambiar sílabas inacentuadas por acentuadas según el mensaje que se desee realzar.

\subsection{El ritmo}

Otra cualidad suprasegmental derivada de la prosodia basada en la duración de los patrones tonales, en palabras de Di Cristo y Hirst (citados por Mora y Asuaje, 2009), es «La organización temporal de las prominencias que participan en la estructuración prosódica de los enunciados» (pp. 57-58). Por ello, esta organización en la duración tonal y la asignación de pausas es lo que permite establecer una relación entre la comprensión de las sílabas y su forma de ser percibidas tanto en los dialectos de una lengua como de una lengua a otra.

\subsection{La entonación}

La entonación se centra en cumplir una función significativa, así Álvarez (2008) considera que la entidad prosódica ocurre en el nivel de la expresión, con una función sistemática que solamente está a cargo de la Fonología y esta «abarca la organización de los sonidos del lenguaje en estructuras y sistemas formales [...]» (p. 86). Para Prieto (2003), 
la entonación cumple dos funciones adicionales a la expresiva: una focalizadora y otra demarcativa. La primera le permite a un hablante escoger una información central según sea su interés, dotándola de prominencia entonativa. Mientras que la función demarcativa indica la estructuración y segmentación del discurso en unidades tonales.

El aspecto medular de esta investigación es el estudio de la entonación en ambas funciones, la focal que consiste en la asignación y establecimiento de prominencias, ya sea dando énfasis tonal o quitando el mismo según su valor semántico-pragmático, es decir, significativo e intencional. Y la demarcativa, porque se considera a los acentos tonales como unidades que permiten emitir significados intencionales en la lengua oral.

\subsubsection{El Foco}

Cruttenden (citado por F. Cantero, M. Martí, S. Cantero y J. Llisterri, 2002) establece que el foco entonativo presenta dos tipos de distinciones: foco ancho y foco estrecho, el primero, desde un punto de vista generativista y con rasgos sintácticos; mientras que el foco estrecho es un elemento con mayor relieve o énfasis tonal, el cual contiene la información más relevante del discurso del hablante y se marca en un segmento de su cadena hablada. Ahora bien, en correspondencia con el análisis que persigue este estudio sobre la función focalizadora de la entonación y su presencia como elemento independiente con respecto al texto, se ha de considerar como objeto de estudio al foco estrecho. Definido como ese fragmento que indica la información más relevante de la cadena discursiva de un hablante y que solo puede ser producido por la intención del mismo a través de prominencias tonales.

\section{Función Informativa}

Sin duda alguna, el hablante hace uso de elementos extralingüísticos con el fin de producir efectos en su interlocutor y, por ello, el acto comunicativo predispone las estrategias que un hablante usa para transmitir sus mensajes. La función pragmática siempre está presente en la interacción comunicativa y esta es explicada por Simone (2001) como la existencia de valores significativos funcionales, que se centran en la emisión informativa y en la perspectiva del receptor, es decir, fijados en el intercambio de ideas que se dan entre un emisor y un receptor. Esto es, que puede darse en una base de conocimientos informativos que son compartidos o nuevos para los interlocutores y de los cuales se construye una red de significados estrechamente relacionados con la actividad enunciativa. Acto que engloba dos estructuras pragmáticas distintas y complejas: una que opera en la selección de temas de conversación (estructura temática) y otra encargada de seleccionar la base de conocimientos compartidos entre los hablantes (estructura de conocimientos). En el intercambio de conocimientos se presentan informaciones que son ya conocidas por el 
receptor (lo dado) y otras que son incluidas por primera vez en los conocimientos del receptor (lo nuevo).

Así pues, resulta pertinente considerar como objeto de estudio los acentos tonales, debido a que estos cumplen funciones no solo de tipo contrastivo, es decir, tonalidades altas o bajas, sino también son marcas de significación pragmáticas en los actos locutivos, según la base de conocimientos informativos. De este modo, la presente investigación se ubica en el marco de la Fonología y del estudio de los recursos extralingüísticos que permiten marcar el foco en las estructuras informativas.

\section{Modelo Métrico Autosegmental (AM)}

En relación con el análisis de los acentos tonales de los focos, se considera el Modelo Métrico Autosegmental (AM), debido a que este permite el estudio de los elementos melódicos en enunciados reales y que puede ser aplicable a cualquier lengua, así como también a sus variedades lingüísticas, tal como es el caso de la presente investigación en el habla de Maracay. En el modelo AM explicado en Hualde (2003), los acentos tonales son los tonos asociados a la sílaba tónica de una palabra, los cuales pueden presentar elementos contrastivos de tipo tonal, tales como: $\mathrm{L}$ (tono bajo- valle) y $\mathrm{H}$ (tono alto- pico).

\subsection{Estudios Previos}

Diversos son los estudios realizados en la lengua española sobre los acentos tonales y su relación con los focos. Para efectos de esta investigación se considera la selección de una serie de estudios realizados en España y en el contexto latinoamericano. De manera que sus resultados permiten ser comparados con los hallazgos de la presente investigación.

En el estudio de Amorós (2004), los resultados reportan una predisposición a la no sincronización del pico tonal con la vocal tónica en las palabras graves y esdrújulas. Así, las palabras agudas fueron las que mostraron sincronización del pico tonal y la sílaba acentuada en un 59\%, mientras que las palabras llanas obtuvieron un $24 \%$ de sincronización y un $46 \%$ de post-realizaciones, y las esdrújulas evidenciaron sincronización en un $26 \%$, pero con pos-realización en un $49 \%$.

Por su parte, Face (2002) determinó que las palabras focales en posición inicial evidenciaron una altura tonal máxima de $197 \mathrm{~Hz}$ y en posición medial $187 \mathrm{~Hz}$, en tanto que las palabras no focales en posición inicial tenían una altura tonal promedio de $201 \mathrm{~Hz}$, y $197 \mathrm{~Hz}$ en posición medial. En la posición final, las palabras no focales arrojaron un valor en la altura tonal de $159 \mathrm{~Hz}$, y las focales al final de frase, una altura tonal de $162 \mathrm{~Hz}$, siendo esta una diferencia reducida entre los valores de las palabras focalizadas y no focalizadas en final de frase. El autor concluye que la primera forma en que la altura tonal marca el foco es de tipo local. 
Burdach y Poblete (2005) obtuvieron como resultados un predominio de los recursos sintácticos con un $64,1 \%$, una utilización de recursos léxicos en un $21,9 \%$, un recurso de reduplicación en un 7,5\% y un recurso de concurrencia en un 6,4\%. Así mismo los resultados permitieron incluir otras categorías en los recursos prosódicos de focalización, además de agruparlos según las categorías de estructura sintáctica especial 53\%, estructura de orden $47 \%$ y dentro de la estructura especial se observó el uso de la pasiva con perífrasis verbal, seguida de las estructuras ecuacionales. Por otro lado, los resultados evidenciaron el uso de focalizadores presuposicionales en un $97,4 \%$ correspondiente a los recursos de tipo léxico.

Díaz y Tevis (2002) encontraron que entre los dialectos de los hablantes chilenos y los peninsulares hay diferencias tonales muy marcadas. Por un lado, los chilenos, en su mayoría, presentan el tono en posición nuclear de tipo $\mathrm{H}+\mathrm{L}^{*}$; mientras que en el tono nuclear de los peninsulares predomina el de tipo $\mathrm{L}^{*}+\mathrm{H}$, pero en otros dialectos se dan en las sílabas prenucleares. En cuanto a los tonos de juntura se determinó que fueron empleados al final de cuatro tipos de unidades propuestas para el análisis. De modo que, los tonos de juntura $\mathrm{H} \%$ son utilizados con mayor frecuencia entre palabras con un $51 \%$; mientras que en los tonos de juntura $\mathrm{M} \%$ y $\mathrm{LH} \%$ no presentaron una elevada frecuencia de utilizaciones en comparación con los tonos $\mathrm{H} \%$. Sin embargo, los tonos M\% tienen una mayor frecuencia entre palabras y en enunciados incompletos con un $26 \%$ y los tonos $\mathrm{LH} \%$ con una mayor repetición en ideas completas, con $04 \%$.

Martín (2006), en su análisis, determinó que las categorías gramaticales y funcionales tienen un papel significativo en la marcación prosódica, pero se dan como melodías no circunflejas (no asociadas a la sílaba acentuada). En las categorías gramaticales determinó: $22 \%$ de frases nominales, $23 \%$ de frases preposicionales, $20 \%$ de verbos, $8 \%$ de adjetivos, $12 \%$ de adverbios y $15 \%$ de varias clases de pronombres. En cuanto a las funciones sintácticas obtuvo: $6 \%$ sujeto, $20 \%$ verbo, $12 \%$ objeto directo, $3 \%$ objeto indirecto, $15 \%$ atributo, $2 \%$ predicativo, $14 \%$ modificador, $23 \%$ circunstancial, y apéndice $2 \%$. En relación con el tipo de verbo, se presentó: como atributivo $22 \%$, transitivo $43 \%$, intransitivo $26 \%$, intransitivo seudo-impersonal $7 \%$ e impersonal $2 \%$. El autor concluye que desde el punto de vista metodológico, el estudio entonativo debe estar relacionado con la dimensión sintáctica, discursiva y comunicativa de los hechos melódicos.

Alfonso, Bartolí, Cantero, Corrales y Vidal (2005), en relación con los resultados obtenidos en la investigación sobre el análisis melódico, circunscritos con el primer pico, la declinación y la inflexión final, y con los resultados del estudio de Cantero (2002) y Cantero et al (2005) obtuvieron que el primer pico evidenció los rasgos de resituación de la inflexión final, ya que el núcleo se desplazó al primer pico. En cuanto a la inflexión 
final, se presentó de tipo simple descendente, y la inflexión final circunfleja evidenció un complejo valor de énfasis por sí misma. En conclusión, consideraron que el énfasis es un fenómeno multifactorial caracterizado por la concurrencia de múltiples rasgos tanto melódicos como no melódicos.

De acuerdo con estos resultados evidenciados en las investigaciones referenciadas, puede decirse que los rasgos prosódicos abarcan diversas estructuras acentuales según las lenguas y sus variedades dialectales. Por ello, nuestro estudio analiza el comportamiento de tipo entonacional en una variedad del español de Venezuela, en la ciudad de MaracayEdo., Aragua, para así determinar su patrón entonativo.

\section{Metodología}

\subsection{Enfoque Metodológico de Investigación}

La investigación está enfocada en el método fonético experimental, que según Llisterri (1991) ha sido utilizado principalmente para los estudios fonéticos. En relación con la aplicación del método fonético, Straka (citado por Llisterri, 1991) presenta dos técnicas de análisis: el de la Fonética instrumental y la Fonética auditiva. En la instrumental se emplea una herramienta de laboratorio para los análisis, y el segundo está basado solo en la percepción auditiva de un investigador experto. De manera que, esta investigación formaría parte del análisis fonético instrumental, debido a que se hace uso de la herramienta computacional para exploración de los datos, a través del programa para el análisis del habla, el Praat 4.0.

\subsection{Corpus}

El estudio parte del Corpus Sociolinguístico de la Ciudad de Maracay con las siglas CSMC, que se inserta en la línea de investigación denominada Lingǘstica del español (en proceso de registro), perteneciente a la Maestría en Lingüística del Instituto Pedagógico de Maracay y adscrito al Centro de Investigaciones Lingüísticas y Literarias «Hugo Obregón MuñoZ» (CILLHOM). Este corpus está integrado por 18 hablantes etiquetados de la siguiente manera: las dos primeras iniciales corresponden a la ciudad de ubicación (Maracay Ciudad), seguido del número del hablante en la serie (1-18), inicial del sexo: femenino o masculino (F-M), número de grupo generacional: primero de 25 a 29 años, segundo de 30 a 39 años, tercero 40 a 49 y cuarto, más de 50 años (1-4), inicial del nivel de escolaridad: básico, diversificado y superior (B, D y S) y por último, la inicial del nivel socioeconómico: bajo, medio y alto (B, M y A), ejemplo: MC4F2BB. 


\subsection{Informantes}

A partir del CSMC se seleccionó un informante de manera intencional, ya que este estudio está orientado hacia el análisis descriptivo de los datos y no es una investigación de tipo sociolingüístico, razón que permite tomar un solo informante porque no se pretende comparar los datos con distintas variables sociolinguísticas o la incidencia de ellas con aspectos fonológicos. El informante seleccionado se encuentra codificado en el CSMC, como: MC4F2BB. La codificación del informante se lee de la siguiente manera: $\mathrm{MC}=$ Ciudad de Maracay, $4=$ Cuarto hablante, $\mathrm{F}=$ Femenino, $2=$ Segundo grupo generacional, $\mathrm{B}=$ Nivel de escolaridad básica y $\mathrm{B}=$ Nivel socioeconómico bajo.

\subsection{La Muestra}

Del informante seleccionado se analizaron los 30 minutos de grabación oral que contiene. De él se segmentaron 636 enunciados con el fin de identificar las unidades con presencia de tema informativo. Los enunciados se organizaron a partir de la codificación establecida en el Corpus Sociolinguístico de Maracay y se adiciona, al final de la etiqueta, la serie enumerativa de los enunciados. De esta manera, en la investigación se presenta la serie de los enunciados del MC2M1SM-01 hasta MC2M1SM-636. La muestra quedó conformada por 162 enunciados, debido a que se eliminaron aquellos enunciados no enunciativos, es decir, los interrogativos y exclamativos, así como también los que presentaban ruido acústico producido por confluencia de las voces del entrevistado y el entrevistador, risas, llanto, suspiros y otros ruidos de fondo en la entrevista, reparaciones, alargamientos, repeticiones y falsos arranques. Se eliminaron también aquellos que no presentaban el tema informativo o aparecían los temas reparados.

Por otro lado, en los enunciados seleccionados, se analizaron los acentos tonales de los focos prosódicos del habla espontánea de Maracay. Así se considera al enunciado como la unidad mínima que subyace en el acto interlocutivo, tal como lo conceptualiza Alarcos (1995), es decir, una estructura con sentido completo que se da en el hecho comunicativo. La segmentación del discurso se da por un cese a la locución al inicio y final de la producción discursiva y determinan así los enunciados según Alarcos (1995).

Véanse los siguientes ejemplos extraídos del CSMC:

MC4F2BB-123 tú no puedes salir

MC4F2BB-124 porque te lanzan una bomba congelada

MC4F2BB-125 tú también no puedes salir

La unidad de análisis es la sílaba acentuada que se ubica en el sintagma temático focalizado. Además, según lo planteado en el modelo de análisis entonativo AM explicado por Hualde (2003), los acentos tonales son aquellos tonos asociados con la sílaba acentuada, y los tonos de frontera son las configuraciones tonales que se dan al final del enunciado. 
En relación con los 162 enunciados de la muestra, se identificó en cada uno de ellos el tema informativo, que en términos de Halliday (citado por Rojo, 1983) no es más que aquella información de la que se habla o quiere hablar el emisor de la secuencia discursiva. Seguidamente, se procedió a establecer la activación de la información en los enunciados, tal como se refiere en apartados anteriores: la información ya conocida como (D) o temas dados, y la información nueva (N).

\subsection{Procedimiento para el análisis del corpus}

En la presente investigación se empleó el procedimiento metodológico utilizado por Cantero et al (2005) para la codificación de enunciados. Y a esta matriz de codificación se le adicionó un apartado para señalar la activación de la información. Como procedimiento estadístico se empleó el programa SPSS (Statistical Packeage for The Social Sciences) que permite el cruce de variables sintáctico-pragmáticas con las prosódicas. El programa estadístico de esta investigación es utilizado principalmente para la obtención de frecuencia y porcentajes en las variables de estudio.

\subsection{Procedimiento para el análisis de los enunciados}

Para la organización de los enunciados y la identificación de sus temas de conversación, se utilizó una matriz de distribución de los enunciados, que permite la marcación de los temas y la marcación de la activación de la información. En la primera columna se presenta el código del hablante descrito anteriormente. En la segunda aparece el enunciado y en él se identifica el sintagma nominal que determina el tema informativo, el cual se marca en negrita. En la tercera columna, se parte del contexto para determinar si la información es nueva (N) o dada (D).Tal como se muestra en el siguiente ejemplo:

Tabla No. 1

Distribución de los enunciados y la activación de la información

\begin{tabular}{|c|l|c|}
\hline Código & \multicolumn{1}{|c|}{ Enunciado } & Act. Infor. \\
\hline MC4F2BB-30 & así soy yo en diciembre & N \\
\hline MC4F2BB-31 & por cierto yo cumplo año en diciembre & N \\
\hline MC4F2BB-34 & yo no tomo licor & N \\
\hline MC4F2BB-35 & yo no bailo & N \\
\hline
\end{tabular}

En la tabla 1 se observa en la primera columna, la codificación de los enunciados, en la segunda aparecen los enunciados y dentro de estos, la identificación del tema que en este caso es el segmento «...yo...». En la última columna se encuentra identificada la activación de la información. Por ello, en el enunciado 30 el hablante se menciona a sí 
mismo como tema por primera vez, y se considera una información nueva, luego en los enunciados sucesivos se observa que aquello de lo que se dice del tema «...yo...» es una información no conocida por el receptor. Por tanto, los enunciados siguientes al 30 se siguen codificando como información nueva $(\mathrm{N})$.

\subsection{Procedimiento para el análisis de los acentos}

Para el análisis de las muestras de audio, se usó el programa computacional Praat 4.0 y las herramientas descargables al mismo: script de figuras y script de etiquetaje ToBi. Con el script de etiquetaje se observa el oscilograma y el espectrograma para editar las muestras de audio, colocando la transcripción ortográfica del enunciado, luego ubicar el foco del enunciado y transcribir fonéticamente la palabra; se identifica en una tercera barra a qué estado de la activación de la información corresponde (N) o (D). En la última barra se coloca la asignación del tono nuclear del foco del enunciado, además del tono de frontera en la frase.

Cabe señalar, que a través del programa se puede identificar en la curva melódica los picos más altos que forman parte del recurso entonativo, elemento que puede visualizarse solo con el uso del programa para procesar voces. Finalmente se genera la imagen con el Script de figuras tal como se muestra a continuación:

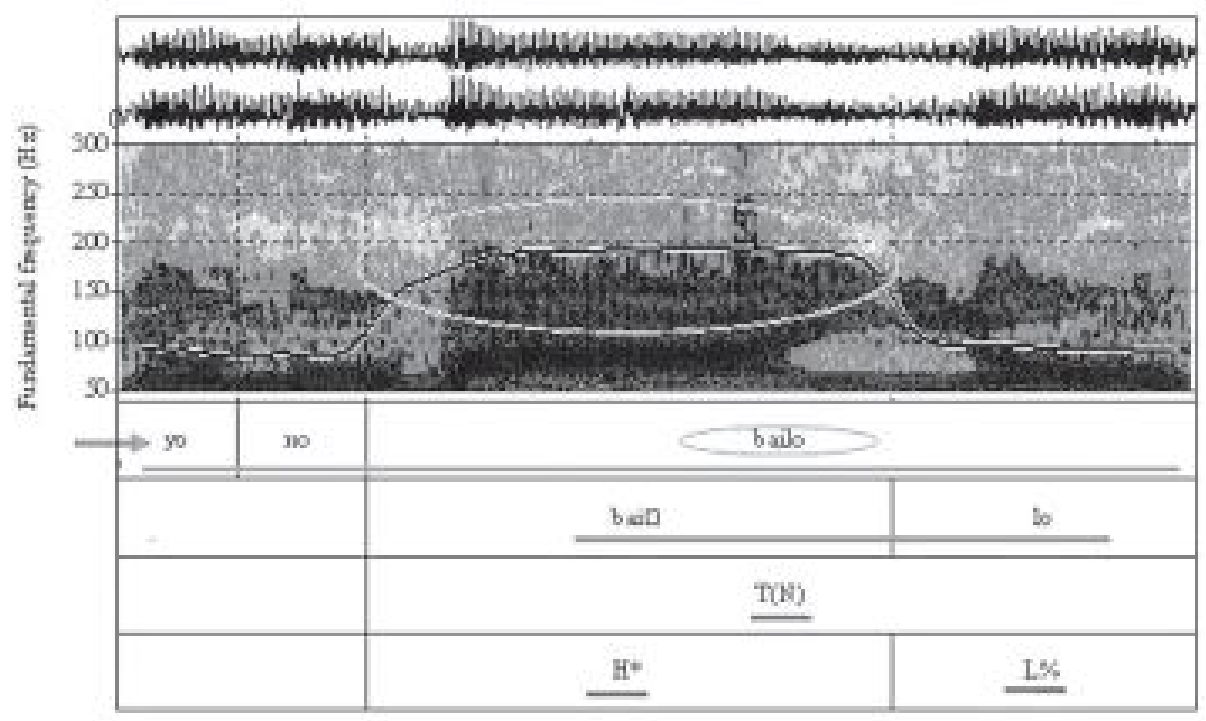

Figura 1. Oscilograma y espectrograma del enunciado «...yo no bailo...» (MC4FBB-35).

Leyenda $=\longrightarrow:$ Recorrido de la curva melódica $\longrightarrow$ Foco: Escritura ortográfica del Enunciado.

: Activación de la información. $\quad$ : Tono asignado. 
Tabla No. 2

Contexto temático informativo del enunciado MC4F2BB-35

\begin{tabular}{|c|l|c|}
\hline Código & \multicolumn{1}{|c|}{ Enunciado } & Act. Infor. \\
\hline MC4F2BB-31 & por cierto yo cumplo año en diciembre & $\mathrm{N}$ \\
\hline MC4F2BB-34 & yo no tomo licor & $\mathrm{N}$ \\
\hline MC4F2BB-35 & yo no bailo & $\mathrm{N}$ \\
\hline
\end{tabular}

\section{Resultados y conclusiones}

En la actualidad se ha procesado un $83.3 \%$ de la muestra oral total, correspondiente a los enunciados con información nueva. En ella se presentan tres tipos de configuraciones tonales: $\mathrm{H}^{*}, \mathrm{~L}+\mathrm{H}^{*}$ y $\mathrm{H}+\mathrm{L}^{*}$. El tono predominante fue el acento $\mathrm{H}^{*}$ en 133 enunciados con un valor porcentual de $82.1 \%$. En función de estos resultados, se infiere que el acento monotonal alto acentuado $\left(\mathrm{H}^{*}\right)$ es un marcador del foco en la información no conocida. Pragmáticamente esto significa que para el hablante, la mayor relevancia informativa se encuentra en aquello que es introducido por primera vez en su discurso, ya que busca centrar la atención del receptor en aquello que le es desconocido.

\section{Referencias bibliográficas}

Alarcos, E. (1995). Gramática de la lengua española. Madrid: Gredos.

Álvarez, A. (1992). Perspectiva Sociolingüística. En: El Idioma Español de la Venezuela Actual. Caracas: Arte, S. A.

Álvarez, A. (2006). Poética del habla cotidiana. Mérida: Consejo de Estudios de Postgrado (CEP) y Consejo de Publicaciones de la Universidad de los Andes.

Amorós, M. (2003). Sincronización entre pico tonal y acento: Resultados según Posición métrica y morfología. Tesis doctoral, Universidad de Granada. Recuperado de http:// www.ub.edu/labfon/XIII-13.pdf

Beaudrie, S. (2005). Refinando la noción de foco en español: cuestiones semánticas y Sintácticas. Recuperado de http://w3.coh.arizona.edu/awp/AWP12 AWP12\%5BBeaudrie\%5D.pdf

Becker, A. (2002). Análisis de la estructura pragmática de la cláusula en el español de Mérida (Venezuela). Estudio de lingüística Española (EliES). Recuperado de http:// elies.rediris.es/elies17/index.htm 
Burdach, A. y Poblete, M. (2005). El fenómeno de focalización en el habla pública de Chile. [Artículo en Línea]. Recuperado de http://onomazein.net/11/ono/11_2.pdf

Cantero, F., Martín M., Cantero, S. y Llisterri, J. (2002). Teoría y análisis de la Entonación. U.B. Edicions Universitat Barcelona. Recuperado de books.google.co.ve/ books?isbn=8483383012..htm

Cantero, F., Alfonso, R., Bartolí, M., Corrales, A y Vidal, M. (2005). Rasgos melódicos de énfasis en español. Phonica. Recuperado de www.publicacions.ub.es/revistes/phonica1/PDF/ articulo_03.pdf

Díaz, M. y Tevis, J. (2002). Entonación en el español de América: un estudio acerca de ocho dialectos hispanoamericanos. Boletín de lingüística, $\mathrm{N}^{\circ} 18$, pp. 3-26. Recuperado de http://redalyc.uaemex.mx/redalyc/pdf/347/34701801.pdf

Face, T. (2002). El foco y la altura tonal en el español. Boletín de Lingüística, $\mathrm{N}^{\circ} 17$, pp. 30-52. Recuperado de http://redalyc.uaemex.mx/../ArtPdfRed.JsP

Gutiérrez, S. (1997). Temas, remas, focos, tópicos y comentarios. Madrid: Arco/libros.

Hualde, J. (2003). El modelo métrico-autosegmental. En: Prieto, P. (ed.): Teorías de La entonación. Barcelona: Ariel Linguística.

Llisterri, J. (1991). Introducción a la fonética: el método experimental. Barcelona: Anthropos.

Martín, P. (2005). La construcción prosódica de la estructura focal en el español. Recuperado de www.ub.edu/labfon/XVII-09.pdf

Martín, P. (2005). (2006). Proyección sintáctico- discursiva de la entonación circunfleja Mexicana. Recuperado de http://lef.colmex.mx/Sociolinguistica/Entonacion\%20del\%20espanol\%20mexicano/ Proyeccion\%20sintactica\%20y\%20discursiva.pdf

Mora, E. y Asuaje, R. (2009). El canto de la palabra: Una iniciación al estudio de la Prosodia. Mérida: Comisión de Desarrollo del Pregrado (CODEPRE)-ULA.

Prieto, P. (2003). Teorías lingüísticas de la entonación. En Prieto, P. (ed.): Teorías de la entonación. Barcelona: Ariel Linguística.

Quilis, A. (1981). Fonética acústica de la lengua española. Madrid: Gredos.

Rojo, G. (1983). Aspectos básicos de sintaxis funcional. Málaga: Ágora, S.A.

Simone, R. (2001). Fundamentos de lingüistica. Barcelona: Ariel. 